\title{
TI.89.1
}

\section{The Co-mingled Universe of R\&E Networking}

- PDF: reconnect-commingled.pdf

- Text: reconnect-commingled.txt

\begin{tabular}{|c|c|}
\hline \multicolumn{2}{|c|}{ More Information } \\
\hline Repository ID & Tl.89.1 \\
\hline Persistent URL & http://doi.org/10.26869/TI.89.1 \\
\hline Title & The Co-mingled Universe of R\&E Networking \\
\hline Authors & Ken Klingenstein \\
\hline Sponsor & SALSA \\
\hline \multicolumn{2}{|l|}{ Review } \\
\hline Status & Legacy \\
\hline Publish Date & October, 2005 \\
\hline DOI & $10.26869 /$ TI.89.1 \\
\hline \multicolumn{2}{|l|}{ Signature } \\
\hline Deprecated & No \\
\hline \multicolumn{2}{|l|}{ Future Review } \\
\hline \multicolumn{2}{|l|}{ Supersedes } \\
\hline Format & PDF, Text \\
\hline \multicolumn{2}{|l|}{ Related Docs } \\
\hline \multicolumn{2}{|l|}{ Development Location } \\
\hline \multicolumn{2}{|l|}{ IP Framework } \\
\hline \multicolumn{2}{|l|}{ Subject Tags } \\
\hline Notes & middlewarerescue \\
\hline
\end{tabular}

